\title{
UM OLHAR FENOMENOLÓGICO DO FEMINICÍDIO NA CONTEMPORANEIDADE
}

\section{A Phenomenological view of the feminicide in conteporaneity}

\author{
Andressa Franceschi de Queiroz - Universidade do Estado do Rio de Janeiro/Brasil \\ Julia Benicio de Andrade - Universidade Federal do Rio de Janeiro/Brasil \\ Juliana Neves Abrantes Santos - Centro Universitário Celso Lisboa/Brasil
}

\begin{abstract}
RESUMO: O presente trabalho tem como principal objetivo discutir o fenômeno do feminicídio à luz do pensamento do filósofo Martin Buber. Pautamos a possibilidade de pensar o referido fenômeno em articulação com a noção de Eu-Isso. Para tanto, inicialmente, realizamos um percurso que engloba uma conceituação do feminicídio e sua ocorrência no cenário contemporâneo e uma discussão sobre as relações entre gêneros. Nas sociedades de regime patriarcal é comum ocorrerem casos de assassinatos de mulheres, seja por cônjuges, familiares ou até mesmo pessoas desconhecidas. As causas destes crimes estão relacionadas ao desejo de posse e da culpabilização pelas mulheres não cumprirem os papeis designados culturalmente. $\mathrm{O}$ assassinato proposital de mulheres cometido por homens consiste numa expressão grave da violência contra a mulher. Nas sociedades patriarcais, a condição de ser mulher se torna um o fator de risco relevante para o feminicídio. O presente trabalho, portanto, traz para a discussão as relações de gênero de forma sucinta, sendo necessário maiores discussões e desenvolvimentos de pesquisas sobre o tema, pois acreditamos que elas constituem um campo muito propício para a ocorrência de relações baseadas em um modo Eu-Isso. Contudo, dentro deste campo mais amplo, situamos o fenômeno do feminicídio, algo que tem sido compreendido como o ápice do controle masculino sobre a vida e a morte da mulher.
\end{abstract}

Palavras-chave: Eu-Tu e Eu-Isso. Feminicídio. Gênero. Martin Buber

ABSTRACT: The present work has as main objective to discuss the phenomenon of feminicide in the light of the thought of the philosopher Martin Buber. We guided the possibility of thinking about this phenomenon in conjunction with the notion of Eu-Isso. To do so, initially, we carried out a journey that encompasses a conceptualization of feminicide and its occurrence in the contemporary scenario and a discussion about the relations between genders. In patriarchal societies, it is common for women to be murdered, whether by spouses, family members or even strangers. The causes of these crimes are related to the desire for possession and to blame women for not fulfilling culturally designated roles. The deliberate murder of women by men is a serious expression of violence against women. In patriarchal societies, the condition of being a woman becomes a relevant risk factor for femicide. The present work, therefore, brings gender relations to the discussion in a succinct way, requiring further discussions and research developments on the topic, as we believe that they constitute a very propitious field for the occurrence of relationships based on an Eu way. -That. However, within this broader field, we situate the phenomenon of femicide, something that has been understood as the culmination of male control over the life and death of women.

Educação, Psicologia e Interfaces, Volume 4, Número 3, p. 1-17, Julho/Setembro, 2020.

ISSN: 2594-5343. DOI: 10.37444/issn-2594-5343.v4i3.291 
Keywords: I-You and I-That. Femicide. Genre.Martin Buber

\section{INTRODUÇÃO}

O presente trabalho tem como principal objetivo discutir o fenômeno do feminicídio à luz do pensamento do filósofo Martin Buber. Pautamos a possibilidade de pensar o referido fenômeno em articulação com a noção de Eu-Isso. Para tanto, inicialmente, realizamos um percurso que engloba uma conceituação do feminicídio e sua ocorrência no cenário contemporâneo e uma discussão sobre as relações entre gêneros.

Tendo em vista os números de casos de feminicídio no Brasil nos últimos anos, torna-se relevante o debate sobre este tema na atualidade. Refletir de que modo as relações têm sido constituídas na sociedade é essencial para entendermos o contexto no qual este fenômeno acontece. Deste modo, este tema faz-se urgente e necessário na pauta atual.

\section{MATERIAL E MÉTODO}

Este estudo trata-se de uma revisão da literatura de Martin Buber a partir da teoria da relação Eu-Tu, Eu- Isso; os princípios do feminismo da literatura da Simone de Beauvoir. Foram utilizados alguns artigos científicos dos anos de 2015 a 2017 para tratar sobre o tema do feminicídio.

Com o intuito de embasar este estudo com dados estatísticos, foram utilizadas fontes que revelam os percentuais de feminicídios praticados no Brasil na atualidade, estes dados foram retirados do Atlas da violência de 2019 e do Anuário da Violência 2019.

Elencamos 2 casos que foram acompanhados pela mídia e teve repercussão nacional marcante de feminicídio no Brasil no intervalo de 10 anos, elegemos o intervalo de 10 anos a fim de analisarmos o cenário social neste intervalo de tempo e se houve mudanças no contexto relacionado à violência contra a mulher.

\section{RESULTADOS E DISCUSSÕES}

\subsection{Sobre o Femicídio ou Feminicídio}

Nas sociedades de regime patriarcal é comum ocorrerem casos de assassinatos de mulheres, seja por cônjuges, familiares ou até mesmo pessoas desconhecidas. As causas

Educação, Psicologia e Interfaces, Volume 4, Número 3, p. 1-16, Julho/Setembro, 2020.

ISSN: 2594-5343. DOI: 10.37444/issn-2594-5343.v4i3.291 
destes crimes estão relacionadas ao desejo de posse e da culpabilização pelas mulheres não cumprirem os papéis designados culturalmente.

A violência contra as mulheres pode ser de caráter físico, psicológico, sexual e patrimonial, ao qual pode culminar na morte por homicídio, denominado de feminicídio.

No seminário internacional realizado em 2005, Feminicídio, Política e Direito, Diana Russel considerou adequada a tradução do inglês "femicide" para o espanhol "femicídio", para evitar a feminização da palavra homicídio. Porém, autores como Marcela Lagarde diferenciam femicídio, ou assassinato de mulheres, de feminicídio, ou assassinato de mulheres pautado em gênero em contextos de negligência do Estado em relação a estas mortes, configurando crime de lesa humanidade (MENEGHEL; PORTELLA, 2017, p. 3079).

O conceito de femicídio foi empregado pela primeira vez por Diana Russel em 1976, no Tribunal Internacional Sobre Crimes Contra as Mulheres, realizado em Bruxelas, a fim de indicar o assassinato de mulheres devido ao fato de serem mulheres, caracterizando o termo como o terrorismo sexual ou genocídio de mulheres. Deste modo, o conceito caracteriza o assassinato de mulheres por homens motivados pelo ódio, desprezo, prazer ou sentimento de propriedade (MENEGHEL; PORTELLA, 2017).

Russel enfatiza a desigualdade de poder entre homens e mulheres, no qual os homens têm a crença de que possuem o direito de dominação nas relações com as mulheres. Deste modo, o feminicídio constitui-se um mecanismo de perpetuação da dominação masculina, o qual se encontra enraizado socialmente e culturalmente (MENEGHEL; PORTELLA, 2017).

$\mathrm{O}$ assassinato proposital de mulheres cometido por homens consiste numa expressão grave da violência contra a mulher. Nas sociedades patriarcais, a condição de ser mulher se torna um o fator de risco relevante para o feminicídio.

A morte das mulheres constitui-se na etapa final de um continuum de terror contra as mulheres, como estupros, escravidão sexual, abuso sexual, violência física e emocional, assédio sexual e até mesmo cirurgias cosméticas e outras mutilações em nome da beleza, dentre outros. De acordo com Russel, sempre que estes terrorismos ocasionarem a morte tem-se um femicídio ou feminicídio.

Alguns fatores podem elevar o risco de as mulheres serem mortas pelos parceiros, como a discrepância de idade entre os cônjuges, situação marital informalizada, tentativas

Educação, Psicologia e Interfaces, Volume 4, Número 3, p. 1-17, Julho/Setembro, 2020.

ISSN: 2594-5343. DOI: 10.37444/issn-2594-5343.v4i3.291 
da mulher de separar-se e episódios de contínua violência e agressão. O femicídio não deve ser atribuído a uma explosão passional ou apenas à doença do agressor, pois retira o sentido social e de gênero do crime (MENEGHEL; PORTELLA, 2017).

Mulheres que têm níveis mais elevados de escolaridade e melhor condição socioeconômica que seus companheiros estão em maior risco, devido ao fenômeno denominado backlash, ou feminicídios cometidos por companheiros ou conhecidos que estão em nível socioeconômico inferior que ao das mulheres ou até mesmo quando elas desejam terminar o relacionamento e eles não desejam. Outro contexto que ocorre em todas as classes sociais e que aumenta o risco de feminicídio é a agressão sexual. A exploração e o tráfico sexual de mulheres e meninas também são fatores de risco (MENEGHEL; PORTELLA, 2017).

\subsection{A Lei Maria da Penha e a Lei do feminicídio}

Em 1993 ocorreu a definição dada pela Declaração sobre a Eliminação da Violência contra a Mulher ao termo "violência contra a mulher". A partir deste momento, a violência baseada no gênero passou a ser especificada. Em 1994, a Convenção Interamericana para Prevenir, Punir e Erradicar a Violência contra a Mulher - Convenção de Belém do Pará foi adotada pela OEA e ratificada pelo Brasil em 1995. O Comitê da CEDAW/ONU recomendou a elaboração de uma legislação específica que tratasse da violência contra a mulher.

Contudo, anteriormente a estes feitos, em 1983, Maria da Penha, uma cidadã brasileira, sofreu uma tentativa de homicídio pelo seu marido que, através de um tiro em suas costas, a deixou paraplégica. Duas semanas após o ocorrido, Maria da Penha sofreu uma nova tentativa de assassinato pelo seu marido que, nessa ocasião, tentou eletrocutála no banho. Após este fato, Maria da Penha decidiu entrar com ação contra o seu marido. Entretanto, mesmo após 15 anos da agressão, ainda não havia uma sentença condenatória pelos Tribunais brasileiros contra o seu marido e o mesmo permanecia em liberdade. (BARACHO; SOUZA, 2015).

Assim, as peticionárias denunciaram a tolerância da violência contra Maria da Penha pelo Estado brasileiro. Em 2001, a Comissão Interamericana de Direitos Humanos responsabilizou o Estado brasileiro por negligência e tolerância à violência doméstica contra as mulheres. Deste modo, a denúncia do caso de Maria da Penha foi uma evidência 
de uma padronização do sistema brasileiro de omissão em relação à violência contra diversas mulheres.

O Caso Maria da Penha foi o primeiro em que a Convenção de Belém do Pará foi aplicada. A utilização desse instrumento internacional (regional) de grande relevância para a proteção e promoção dos direitos humanos das mulheres e o seguimento das peticionárias perante $\mathrm{CIDH}$ sobre o cumprimento da decisão pelo Estado brasileiro foram decisivas para que o processo fosse concluído em âmbito nacional e, posteriormente, para que o agressor fosse levado à prisão em outubro de 2002. (...). Em 2004, foi criado o Grupo de Trabalho Interministerial, o qual foi coordenado pela ministra Nilcéa Freire, com o objetivo de elaborar proposta de medida legislativa e outros instrumentos para coibir a violência doméstica contra a mulher. (...) Com a realização de audiências em âmbito regional e nacional, inclusive no Congresso Nacional, conseguiu-se a aprovação da Lei n. 11.340/06, a qual trata de maneira específica a violência doméstica e familiar contra as mulheres - Lei Maria da Penha, "como é carinhosamente chamada e conhecida por todos (...) (BARACHO; SOUZA, 2015, p. 85).

Esta Lei obriga o Estado a intervir contra qualquer tipo de agressão às mulheres ou meninas. A Lei abrange a criação de um sistema integral de prevenção, proteção e assistência para as mulheres, além de estabelecer parâmetros e obrigações do Estado na instância federal, estadual e municipal.

A Lei Maria da Penha contempla o conceito da violência de gênero em várias dimensões: física, psicológica, patrimonial, econômica, trabalhista, institucional, sexual e de matrimônio. De acordo com esta, o Estado deverá destinar recursos financeiros para realizar trabalhos de combate à violência contra as mulheres. Dessa forma, atualmente qualquer pessoa pode denunciar casos de violência contra a mulher (BARACHO; SOUZA, 2015).

Um ano após a promulgação da Lei Maria da Penha, as taxas de homicídio de mulheres caíram. Todavia, a partir de 2008, retomou aos índices anteriores. Assim, somente uma década depois, foi iniciada no Brasil uma discussão sobre a necessidade de uma lei específica para o feminicídio. O crime de feminicídio foi sancionado através da Lei 13.104/15. A nova lei alterou o código penal a fim de incluir mais uma categoria de homicídio qualificado, o feminicídio, quando o crime for praticado contra a mulher pela condição de ser do sexo feminino. Deste modo, a questão do gênero passou a qualificar um tipo específico de homicídio. Destarte, o feminicídio constitui uma circunstância

Educação, Psicologia e Interfaces, Volume 4, Número 3, p. 1-17, Julho/Setembro, 2020.

ISSN: 2594-5343. DOI: 10.37444/issn-2594-5343.v4i3.291 
qualificadora do homicídio e está incluso na lista de crimes hediondos (crimes graves e com alto índice de crueldade). Apesar de todos estes avanços no combate a violência contra a mulher, devemos refletir sobre a demora do Estado em criar uma lei específica e dura para o enfrentamento de tal violência (BARACHO; SOUZA, 2015).

De acordo com o Atlas da violência (IPEA, 2019), ocorreu um aumento considerável dos homicídios femininos no Brasil em 2017, com cerca de 13 assassinatos por dia. No total, 4.936 mulheres foram mortas. Este foi o número mais elevado registrado desde o ano de 2007. Deste modo, ocorreu um crescimento de $\mathbf{3 0 , 7 \%}$ no número de homicídios de mulheres no país durante a década de (2007-2017).

Entre 2007 e 2017 houve aumento de $\mathbf{2 0 , 7 \%}$ na taxa nacional de homicídios de mulheres, quando a mesma passou de $\mathbf{3 , 9}$ para $\mathbf{4 , 7}$ mulheres assassinadas por grupo de $\mathbf{1 0 0}$ mil mulheres. Nesse período, houve crescimento da taxa em $\mathbf{1 7}$ Unidades da Federação. Já no recorte de 2012 a 2017, observamos aumento de $\mathbf{1 , 7 \%}$ na taxa nacional e um aumento maior ainda de $\mathbf{5 , 4 \%}$ no último ano, período em que se verificam taxas ascendentes em 17 UFs em relação a 2016. Considerando o período decenal, Rio Grande do Norte apresentou o maior crescimento, com variação de $\mathbf{2 1 4 , 4 \%}$ entre 2007 e $\mathbf{2 0 1 7}$, seguido por Ceará (176,9\%) e Sergipe (107,0\%). Já no ano de 2017, o estado de Roraima respondeu pela maior taxa com 10,6 mulheres vítimas de homicídio por grupo de $\mathbf{1 0 0}$ mil mulheres, índice mais de duas vezes superior à média nacional $(\mathbf{4 , 7})$. A lista das unidades federativas onde houve mais violência letal contra as mulheres é seguida por Acre, com taxa de 8,3 para cada $\mathbf{1 0 0}$ mil mulheres, Rio Grande do Norte, também com taxa de 8,3, Ceará, com taxa de 8,1, Goiás, com taxa de 7,6, Pará e Espírito Santo com taxas de 7,5. (IPEA, 2019, p.36, grifos nossos).

Cabe ressaltar que a taxa de homicídios de mulheres não negras teve crescimento de $\mathbf{4 , 5 \%}$ entre 2007 e 2017 , a taxa de homicídios de mulheres negras cresceu $\mathbf{2 9 , 9 \%}$. Assim, os homicídios de mulheres não negras tiveram um aumento de $\mathbf{1 , 7 \%}$ e entre mulheres negras de $\mathbf{6 0 , 5 \%}$. No total das vítimas da violência letal $\mathbf{6 6 \%}$ de todas as mulheres assassinadas no país em 2017 são negras. Evidenciando a enorme dificuldade do Estado brasileiro de garantir a universalidade das políticas públicas.

Uma questão relevante está relacionada à percepção do aumento nos casos de feminicídios no país. A Lei do Feminicídio (Lei n 13.104, de 09/03/2015) é recente, assim, os registros de feminicídio das Polícias podem conter alguma subnotificação, em função da não imputação do agravante de feminicídio.

De acordo com o Anuário de violência (2019), ocorreram 1075 feminicídios e 4.556 homicídios contra as mulheres que não foram classificados como feminicídios no

Educação, Psicologia e Interfaces, Volume 4, Número 3, p. 1-16, Julho/Setembro, 2020. ISSN: 2594-5343. DOI: 10.37444/issn-2594-5343.v4i3.291 
ano de 2017. No ano de 2018 houve $\mathbf{1 , 2 0 6}$ casos de feminicídios e 4.107 homicídios contra as mulheres que não foram classificados como feminicídios. O que corrobora a necessidade de uma ampliação da percepção e da notificação correta dos crimes cometidos contra as mulheres.

\subsection{Casos marcantes de feminicídio no Brasil no intervalo de 10 anos}

Há 11 anos, em 2008, um caso paralisou o país e todos os canais de televisão. O caso da jovem Eloá Cristina Pimentel ${ }^{1}$, de 15 anos. Eloá ficou presa no apartamento em que morava, em São Paulo. Ela foi mantida refém pelo ex-namorado, Lindemberg Alves Fernandes, de 22 anos, que entrou armado na residência, pois não aceitou o fim do relacionamento.

Lindemberg entrou no apartamento onde Eloá estudava com três amigos - Nayara Rodrigues, Iago Vilera e Victor Campos. Lindemberg liberou os dois rapazes na mesma noite. No dia seguinte, Nayara deixou o apartamento, mas retornou ao cativeiro para ajudar nas negociações. Após aproximadamente 100 horas, durante quatro dias, a polícia invadiu o apartamento e Lindemberg atirou contra as duas meninas. Eloá morreu, Nayara foi atingida, mas sobreviveu. Lindemberg foi condenado a 98 anos de prisão pelo assassinato da ex-namorada, e por mais 11 crimes cometidos durante o sequestro. Um ano depois, a pena foi reduzida para 39 anos.

Após 11 anos do assassinato da jovem Eloá, o cenário em relação ao feminicídio pouco mudou no Brasil. Recentemente, ${ }^{2}$ a advogada Tatiane Spitzner foi encontrada morta em 22 de julho de 2019, no apartamento em que morava com seu esposo em Guarapuava. A Polícia Militar recebeu uma denúncia de que uma mulher teria saltado ou sido jogada de um prédio e encontrava-se caída na calçada.

\footnotetext{
1 Informações retiradas do site Metro ABC,escrito por Cadu Proieti e Diego Brito/ Disponível em https://www.metrojornal.com.br/foco/2018/10/15/caso-eloa-10-anos-apos-assassinato-da-jovem-combateao-feminicidio-pouco-mudou.html
}

\footnotetext{
2 Informações retiradas do site G1 PR e RPC Guarapuava por Wesley Bischoff /Disponível em https://g1.globo.com/pr/campos-gerais-sul/noticia/2019/03/21/caso-tatiane-spitzner-marido-reu-porfeminicidio-e-interrogado-nesta-quinta.ghtml
}

Educação, Psicologia e Interfaces, Volume 4, Número 3, p. 1-17, Julho/Setembro, 2020. ISSN: 2594-5343. DOI: 10.37444/issn-2594-5343.v4i3.291 
Contudo, testemunhas relataram a polícia que um homem teria carregado o corpo para dentro do prédio. De acordo com a PM, o corpo da advogada foi encontrado dentro do apartamento. Em vários canais da televisão aberta do Brasil, foram exibidas as gravações das câmeras de segurança do prédio, que mostram o marido, Luis Felipe Manvailer, agredindo a mulher de forma brutal, após uma discussão. De acordo com a MP-PR, Luis Felipe matou a mulher por esganadura. Após isso, ele jogou o corpo da advogada pela sacada do prédio onde moravam, recolheu o corpo e o levou de volta para o apartamento. O réu foi preso algumas horas depois do crime. Manvailer é réu no processo por homicídio qualificado (feminicídio), cárcere privado e fraude processual.

Destarte, num período de mais de uma década, podemos observar que casos como o de Eloá continuam acontecendo em nosso país. Mulheres continuam sendo mortas e os dados apontam que esta violência vem aumentando nos últimos anos. Precisamos questionar que tipos de políticas públicas estão sendo implementadas, e de que modo estamos combatendo este tipo de violência.

\subsection{O que é Feminismo}

A despeito da criação das duas Leis anteriormente citadas, o cenário social segue marcado pela frequência dos casos de violência contra as mulheres. Contudo, a possibilidade de nomeá-los de maneira diferenciada e, com isso, dar-lhes a visibilidade necessária, resulta dos esforços empreendidos pelo movimento feminista. O feminismo (do latim femŭna, significa "mulher”) é um conceito que surge no século XIX, o qual se desenvolveu como movimento filosófico, social e político. Sua principal característica é a luta pelo reconhecimento de direitos para as mulheres e a igualdade dos gêneros.

O termo feminismo foi usado primeiro nos Estados Unidos. O objetivo das feministas americanas era buscar uma relação mais justa entre homens e mulheres, reivindicando seus diretos por uma vida mais justa.

Cabe ressaltar que, ao longo da história da sociedade ocidental, os discursos de desigualdade entre homens e mulheres foram validados. Por esta razão, as feministas querem mostrar que o movimento tem uma longa história como movimento social, sendo capaz de impugnar, criticar, desestabilizar e mudar a relação injusta que foi construída entre homens e mulheres. De uma forma ampla, podemos dizer que cada vez que as 
mulheres, individual ou coletivamente, criticam o que o patriarcado lhes impõe e reivindicam seus direitos pela igualdade, estamos diante de uma ação feminista.

A autora Carla Cristina Garcia define feminismo em seu livro Breve História do Feminismo da seguinte forma:

Deste modo, o feminismo pode ser definido como a tomada de consciência das mulheres como coletivo humano, da opressão, dominação e exploração de quem foram e são objeto por parte do coletivo de homens no seio do patriarcado sob suas diferentes fases históricas, que as move em busca da liberdade de seu sexo e de todas as transformações da sociedade que sejam necessárias para o seu fim. Partindo desse princípio o feminismo se articula como filosofia política e, ao mesmo tempo, como movimento social (GARCIA, 2011, p.14).

O discurso e prática feminista carregam uma ética e uma forma de estar no mundo, além de ser uma prática social. O movimento liderado pelas mulheres abrange reivindicações contra atitudes sustentadas e motivadas pelo machismo na sociedade. Dessa forma, o feminismo tem como objetivo construir uma sociedade igualitária com o fim do machismo enraizado.

\subsection{O surgimento do feminismo}

No século XIX as mulheres foram se moldando em uma sociedade patriarcal. Eram vistas como inferior aos homens, não possuíam os mesmos direitos e privilégios que eles, não tinham direito de freqüentar a escola, consequentemente não sabiam ler nem escrever. Relegadas ao espaço doméstico com pouca possibilidade de escolha sobre a própria vida.

Estima-se que o movimento feminista tenha surgido após a Revolução Francesa em 1789. Porém, fortaleceu-se de fato na Inglaterra e foi assumido, mais tarde, pelos Estados Unidos.

No século XX, já na América do Norte, a organização começa a traçar objetivos claros na luta. No ano da Revolução Francesa havia um documento chamado "Declaração dos Direitos do Homem e do Cidadão", o qual excluía claramente a mulher enquanto detentora de direitos e vontades. Contudo, a feminista francesa Olympe de Gouges (17481793) escreveu o documento "Declaração dos Direitos da Mulher e da Cidadã", combatendo a declaração feita exclusivamente para homens. Além disso, denunciava o autoritarismo masculino e enfatizava a importância das mulheres e da igualdade de

Educação, Psicologia e Interfaces, Volume 4, Número 3, p. 1-17, Julho/Setembro, 2020. 
direitos. Por esse documento, Olympe de Gouges foi executada em Paris, em 03 de novembro de 1793. Sua morte passou a ser considerada um marco do feminismo e culminou com o surgimento de diversos movimentos feministas pelo mundo.

Com a Revolução Industrial, no século XIX, há uma mudança neste quadro: as mulheres começam a ocupar lugares nas fábricas, ajudando a movimentar a economia. Aos poucos, os movimentos feministas espalhados pelo mundo começam a se articular e a ganhar força, reivindicando direitos iguais entre os gêneros, como direito a educação, ao voto, ao divórcio, ao aborto, igualdade de salário, fim do casamento arranjado, dentre outros.

O feminismo proporciona a tomada de consciência e transforma a vida das mulheres, pois com a consciência da discriminação pode-se adotar uma postura diferente. Visa enxergar os micromachismos como manobras realizadas diariamente para manter as mulheres sob seu poder, sendo coisificada na publicidade, estafada com jornadas duplas, sofrendo maus-tratos e/ou abuso físico e psicológico.

Não é possível recuperar, ainda que brevemente, a trajetória do movimento feminista sem mencionar aquela que é considerada um dos nomes mais importantes da chamada segunda onda do movimento, Simone de Beauvoir. É importante ressaltar que o interesse de Beauvoir, inicialmente, era o de realizar um estudo filosófico sobre a experiência de ser mulher e não propriamente uma obra de caráter feminista. Entretanto seus escritos lançaram luz à questão da desigualdade entre os sexos.

\subsection{O Feminismo no Brasil}

No Brasil do século XIX, as mulheres negras eram mantidas na condição de escravas e as mulheres brancas viviam em condições desiguais às dos homens, sendo relegadas às tarefas domésticas. Após o fim da escravidão, surge o movimento feminista, juntamente com a luta pelo direito ao voto e pela educação.

Dentre os nomes desta época, pode-se destacar o da escritora Nísia Floresta Augusta como precursora do movimento feminista brasileiro. Ela era professora e educadora e fundou a primeira escola para meninas no Rio Grande do Sul e no Rio de Janeiro. Nísia Augusta redigiu vários livros e artigos nos jornais da época sobre feminismo, abolicionismo e sobre a república. Também escreveu Conselhos a minha 
filha, de 1842 e Opúsculo humanitário, de 1853 que são apontadas como as primeiras literaturas sobre o feminismo brasileiro.

Em alguns países começa um movimento que reivindica o direito das mulheres ao voto. O Brasil entra nesse movimento e torna-se conhecido o caso de Isabel Mattos Dalton que era dentista e diplomata, características que lhe conferiam tal direito. Também se destacam personalidades como Chiquinha Gonzaga, pianista e compositora, que não usava pseudônimo masculino para assinar suas obras.

\title{
3.8 Feminicídio e atitude Eu-Isso
}

No intento de fomentar o debate acerca daquilo que julgamos estar no cerne da relação desigual entre homens e mulheres, lançamos mão das contribuições do filósofo Martin Buber (1878-1965). Húngaro naturalizado israelita, seu pensamento tem influenciado estudos nas áreas da Educação, Sociologia, Direito e Psicologia bem como as psicoterapias de inspiração existencial-humanista, sobretudo a abordagem da Gestaltterapia.

Zuben (2001), tradutor da obra Eu-Tu de Martin Buber para língua portuguesa, explica que sua filosofia toma a relação como principal fundamento da existência humana. O diálogo e a atitude face-a-face são tematizados por ele como eventos do entre, a dimensão ontológica onde se dá o encontro entre as alteridades. Ainda segundo o mesmo autor:

\begin{abstract}
A ontologia da relação será o fundamento para uma antropologia que se encaminha para uma ética do inter-humano. Diz-se então que o homem é um ente de relação ou que a relação lhe é essencial ou fundamento de sua existência. Com isso assistimos ao encontro do pensamento de Buber com a tradição fenomenológica, na medida em que grande parte dos filósofos que a ela pertencem partem também deste princípio do homem como ser situado no mundo com o outro. $\mathrm{O}$ maior mérito que cabe a Martin Buber está no fato de ter acentuado de um modo claro, radical e definitivo as duas atitudes distintas do homem face ao mundo ou diante do ser [...] (ZUBEN, 2001, p.25).
\end{abstract}

De acordo com Hycner (1995), o entre, esta dimensão constitutiva da existência humana tem sido, ao longo de nossa tradição ocidental, negligenciada em virtude da cisão entre interno-externo, objetivo-subjetivo.

Educação, Psicologia e Interfaces, Volume 4, Número 3, p. 1-17, Julho/Setembro, 2020.

ISSN: 2594-5343. DOI: 10.37444/issn-2594-5343.v4i3.291 
No campo das psicoterapias, a teoria de Buber inspira uma "mudança de paradigma dos modelos psicológicos do self isolado ou da abordagem sistêmica para a esfera do inter-humano" (HYCNER, 1995, p.23).

Para Zuben (2001), o pensamento buberiano demonstra um grande compromisso com a realidade concreta, onde o vivido tem primazia sobre qualquer conhecimento conceitual que se queira propor. O autor afirma ainda que a obra de Buber "não se deixa etiquetar por qualquer sistema doutrinário conhecido", apesar de admitir que talvez seja possível aproximá-la da corrente filosófica denominada Filosofia da Vida (ZUBEN, 2001, p. 16).

Como afirma Hycner (1995), a filosofia do diálogo expressa uma preocupação de Martin Buber com uma espécie de racionalidade técnica que passou a reger a sociedade moderna e que repercute sobre a esfera do relacional, produzindo um apagamento dessa. A partir desta constatação, o filósofo estabelece dois modos de ser da relação, os quais nomeou como palavras-princípio Eu-Tu e Eu-Isso.

A atitude $E u$-Tu pauta-se pelo reconhecimento da singularidade do outro e pela reciprocidade, onde o $E u$ só é possível pela existência do $T u$, pois este o introduz algo que não havia antes. Como afirma Zuben:

$T u$ se apresenta ao $E u$ como sua condição de existência, já que não há $E u$ em si, independente, o si-mesmo não é substância, mas relação. $E u$ se torna $E u$ em virtude do Tu. Isto não significa que devo a ele meu lugar. Eu lhe devo a minha relação (ZUBEN, 2001, p.27).

O modo $E u$ - $T u$, também pode ser caracterizado como o modo de ser da criação, do desdobramento de possibilidades, do devir, onde não figura a dicotomia sujeito-objeto. Sendo, pois, encontro desproposital, não se pauta pela utilidade e tampouco pela causalidade (FONSECA, 2019).

Em contrapartida, Eu-Isso se apresenta como o modo de ser que dá suporte à experiência. É a atitude cognoscitiva, da reflexão sobre o fato, a coisa acontecida (Fonseca, 2019), também importante para a organização do mundo e da vida prática. Como exemplo, temos a linguagem e a cultura, forjadas numa atitude Eu-Isso. Sobre esse ponto, Buber explica:

Afirma-se que o homem experiencia o seu mundo. O que isso significa? $\mathrm{O}$ homem explora a superfície das coisas e as experiencia. Ele adquire 
delas um saber sobre a sua natureza e constituição, isto é, uma experiência. Ele experiencia o que é próprio às coisas. Porém, o homem não se aproxima do mundo somente através de experiências. Estas lhe apresentam apenas um mundo constituído por Isso, Isso e Isso, de Ele, Ele e Ela, de Ela e Isso [...] (BUBER 1965/2001, p.44).

Nesta passagem, pode-se compreender que se a atitude Eu-Isso é em certa medida necessária, deve-se evitar cometer o equívoco de caracterizá-la essencialmente como danosa. No entanto, como adverte o próprio Buber (1965/2001): "Se o homem não pode viver sem o Isso, não se pode esquecer que aquele que vive só com o Isso não é o homem". É, portanto, uma predominância da atitude Eu-Isso, a dificuldade de alternância com o modo $E u-T u$ que se torna nociva.

Fonseca (2019) utiliza a expressão cronificação do Eu-Isso para designar a predominância desta atitude e seus potenciais danos, principalmente para o âmbito das relações humanas. Progressivamente viciosa e repetitiva, a atitude Eu-Isso tende a eliminar as possibilidades de criação do novo, o que acarreta o empobrecimento da própria existência.

Buber caracteriza ainda mais a atitude Eu-Isso e, na passagem que se segue, podemos compreender como certa "tendência" à cronificação pode revelar, na verdade, um embate do ser com a indeterminação da existência:

Sem dúvida, alguém que se contenta, no mundo das coisas, em experienciá-las e utilizá-las erigiu um anexo e uma superestrutura de idéias, nos quais encontra um refúgio e uma tranquilidade diante da tentação do nada. Deposita na soleira a vestimenta da cotidianeidade medíocre, envolve-se em linho puro e reconforta-se na contemplação do ente originário ou do dever-ser, no qual sua vida não terá parte alguma. Poderá, até mesmo, sentir-se bem em proclamá-lo (BUBER, 1965/2001, p.50).

Seria possível traçar correspondências entre o pensamento de Buber e de outros filósofos da tradição existencialista. No entanto, para tentar dar conta desta tarefa, seria necessário estender a discussão, algo que escapa aos objetivos deste trabalho. Contudo, cabe assinalar uma ideia fundamental: a de que, para Buber, também estão em jogo questões como a indeterminação da existência, liberdade e destino, arbitrariedade e fatalidade. Quando nos aferramos ao mundo do "Isso": ordenado e previsível estamos também encerrando a existência, negando o seu caráter de poder-ser como nos diz

Educação, Psicologia e Interfaces, Volume 4, Número 3, p. 1-17, Julho/Setembro, 2020.

ISSN: 2594-5343. DOI: 10.37444/issn-2594-5343.v4i3.291 
Heidegger. De modo que, assumir permanentemente uma atitude Eu-Isso equivale dizer que se vive na impessoalidade.

Destarte, parece-nos bastante problemático pensar o campo das relações humanas, de um modo geral, governado por um modo Eu-Isso, onde o outro passa a ser tomado não enquanto alteridade, desdobramento de possibilidade e sim enquanto objeto. Para Buber (1965/2001, p.50) “[...] Objeto não é duração, mas estagnação, parada, interrupção, enrijecimento, desvinculação, ausência de relação, ausência de presença".

\section{CONSIDERAÇÕES FINAIS}

O presente trabalho, portanto, traz para a discussão as relações de gênero de forma sucinta, sendo necessário maiores discussões e desenvolvimentos de pesquisas sobre o tema, pois acreditamos que elas constituem, conforme os dados anteriormente apresentados, um campo muito propício para a ocorrência de relações baseadas em um modo Eu-Isso. Contudo, dentro deste campo mais amplo, situamos o fenômeno do feminicídio, algo que tem sido compreendido como o ápice do controle masculino sobre a vida e a morte da mulher.

A partir das contribuições de Martin Buber, pensamos ser possível compreender este fenômeno como resultado de uma espécie de cronificação ${ }^{3}$, de um modo Eu-Isso de ser nas relações de gênero. Neste tipo de interação, a mulher é relegada à condição de item, de objeto manipulável pelo homem, assinalando a impossibilidade deste de suportála em sua alteridade.

Ocorre que, ontologicamente, não é concebível se relacionar com o outro tal como se lida com os objetos diversos do mundo. Ao se relacionar com o outro, é necessário considerá-lo enquanto ser. Dito de outro modo significa considerar que sua existência não está condicionada à vontade de outrem. Ela é desdobramento de possibilidades e não fatalidade; é movimento em direção a algo, isto é, o próprio destinar-se.

Efetuar um destino, aqui compreendido enquanto ir em direção a alguma coisa implica em liberdade. Neste sentido, a noção de liberdade comparece no pensamento de Buber através da relação $E u$-Tu. Estabelecer relações $E u$-Tu quer dizer reconhecer o outro

\footnotetext{
${ }^{3}$ Aqui tomamos de empréstimo esta expressão de Afonso Fonseca para articular uma discussão acerca da questão de gênero tendo o fenômeno do feminicídio como principal foco de interesse.
} 
em sua alteridade, logo, como radicalmente livre. Tem-se, portanto, o par liberdadedestino se conjugando mutuamente e conformando um modo de ser $E u$ - $T u$ nas relações.

Todavia, o cenário das relações entre gêneros evidencia o cerceamento da liberdade da mulher. É interessante observar como, por meio de uma atitude Eu-Isso, se instaura na diferença uma desigualdade, produzindo uma dominação do masculino sobre

o feminino. À mulher não é permitido ser livre, ir ao encontro de seu destino. É forçada ao modo de ser da repetição dos padrões, da coisa dada, pois somente nestas condições é possível ao homem relacionar-se com ela na sociedade patriarcal. Assim, o feminicídio nos informa que o masculino somente autoriza a existência do feminino mediante o cumprimento de certas regras. Do contrário, coloca-se um ponto de parada definitivo e arbitrário à liberdade de querer da mulher por meio do encerramento de sua vida.

Contudo, apesar de historicamente as relações entre gêneros envolverem acentuada opressão e dominação praticada pelo masculino, não é possível dizer que o feminino se coloca de maneira passiva nesse cenário. Como vimos os esforços empreendidos pelos movimentos de mulheres no sentido de reivindicar direitos têm produzido uma necessidade de se reinterpretar a relação entre gêneros, lançando principalmente uma reflexão mais apurada sobre a concepção de masculinidade que tem autorizado essa desigualdade de condições de existência entre homens e mulheres.

\section{REFERÊNCIAS BIBLIOGRÁFICAS}

BARACHO, L.F; SOUZA, M.C. A Lei Maria da Penha: Égide, evolução e jurisprudência no Brasil. Revista eletrônica do curso de Direito-PUC Minas, Serro, n.11, p.79-106. 2015. Disponível em: http://periodicos.pucminas.br/index.php/DireitoSerro/article/view/8695. Acesso em 15 out.2019.

BRASIL, Lei nº 11.340, de 7 de agosto de 2006, (Lei Maria da Penha).

BRASIL. Lei no 13.104, de 09 de março de 2015, Brasília, DF.

BUBER, M. Eu e Tu, 1878 - 1965. Tradução do alemão, introdução e notas por Newton Aquiles Von Zuben, São Paulo: Centauro, 2001.

CERQUEIRA, D. R. C. et al. Atlas da Violência. Nota Técnica IPEA, n. 20, Brasília: 2019. Disponível em:

http://www.ipea.gov.br/portal/index.php?option=com_content\&view=article\&id=34784 \&Itemid=432 Acesso em: nov. de 2019. 
FONSECA, A.H.L. Curso Buber, 2019 [vídeo]. Disponível em https://www.youtube.com/watch?v=VdPrMlJ97uw\&list=PLEpggrfK5UJmEY_3EFi7yjlughNCiD0R .Acesso em: nov. de 2019.

FÓRUM BRASILEIRO DE SEGURANÇA PÚBLICA - FBSP. Anuário Brasileiro de Segurança Pública. Edição XIII. São Paulo, 2019. Disponível em: http://www.forumseguranca.org.br/wp-content/uploads/2019/10/Anuario-2. 10.19.pdf . Acesso em: nov. de 2019.

GARCIA, C.C. Breve História do Feminismo. Editora Claridade, São Paulo, 2011. HYCNER, R. De pessoa a pessoa: Psicoterapia Dialógica. Summus Editorial, São Paulo, 1995.

MENEGHEL, S.N; PORTELA, A.P. Feminicídios: conceitos, tipos e cenários. Ciênc. saúde coletiva [online]. vol.22, n.9, pp.3077-3086.2017. Disponível em: https://doi.org/10.1590/1413-81232017229.11412017. Acesso em 19 nov.2019 RIBEIRO, W. F.R. Existência essência: desafios teóricos e práticos das psicoterapias relacionais. São Paulo: Summus, 1998.

SILVA, A. Simone de Beauvoir. A mulher como pilar de si mesma. Notícias Instituto Humanitas Unisinos, 08. Jan. 2019. Disponível em: www.ihu.unisinos.br/78noticias/585794-simone-de-beauvoir-a-mulher-como-pilar-de-si-mesma. Acesso em : nov. de 2019.

\section{Credenciais da/os autora/es}

QUEIROZ, Andressa Franceschi. Graduada em Psicologia (UCL), Mestre em Políticas Públicas e Formação Humana (UERJ). Orcid :0000-0002-7085-2562. E-mail: dessafranceschi@hotmail.com/

ANDRADE, Julia Benicio de. - Graduada em Psicologia (UERJ). Psicóloga clínica na Universidade Federal do Rio de Janeiro. Especializada em Gestalt-terapia (UCL). Orcid:0000-00002-5191-4254. E-mail : benicio.julia@gmail.com

SANTOS, Juliana Neves Abrantes. -Graduada em Psicologia. Especializada em Gestaltterapia (UCL). Orcid: 0000-0003-0444-5413 E-mail: juliana-abrantes@ hotmail.com

Endereço para correspondência: Andressa Franceschi de Queiroz. Rua Empírico, 75. Santa Terezinha. Mesquita. CEP 26554450, Rio de Janeiro. E-mail: dessafranceschi@hotmail.com

Como citar este artigo (Formato ABNT): QUEIROZ, Andressa Franceschi; ANDRADE, Julia Benicio de; SANTOS, Juliana Neves Abrantes. Um olhar fenomenológico do feminicídio na contemporaneidade. Educação, Psicologia e Interfaces, v. 4, n.3, p. 1-16, 2020.

Recebido: $07 / 02 / 2020$.

Aceito: 20/04/2020. 